\section{Klippel-Trénaunay Syndrome and Spinal Arteriovenous Malformations: An Erroneous Association}

I read with interest the article entitled "Klippel-Trénaunay Syndrome and Spinal Arteriovenous Malformations: An Erroneous Association" by Alomari et al. ${ }^{1}$ The classification of Klippel-Trénaunay syndrome (KTS) in the complex group of segmental angiomatous phakomatoses based on data from meta-analyses and the findings of 208 patients with the diagnosis KTS is commendable and important with respect to the diagnostic lack of clarity in the classification of overgrowth disorders.

It is, however, a difficult task to precisely define from the material described in 24 publications whether combinations of KTS and spinal arteriovenous malformation (AVM) exist or can be ruled out. The statement capability of a meta-analysis, which usually can confirm modifications or trends, thus appears overtaxed. Likewise, mention of the clinical or radiologic data of 208 patients at the Vascular Anomalies Center at Children's Hospital Boston, when these data are not presented, is not suitable to support the central statement of the article that in principle, no combination of KTS and spinal AVMs exists. The Boston patient data leave unanswered the decisive question of which imaging diagnostics were used to rule out spinal AVMs.

Our own case report ${ }^{2}$ confirms, in my opinion, that KTS may be combined with spinal AVMs in the form of a Klippel-Trénaunay-
Weber syndrome. Our patient presented all criteria of KTS, such as port-wine stain, congenital varices, lymphatic edema, and hypertrophy of soft tissue and of a lower extremity with additional extensive intraspinal and paraspinal AVMs (Fig 1). The observations of $>16$ years to date after embolization of 17 spinal (T7-L5) and paraspinal feeding arteries in this patient shows a largely normal physical development without exponential growth of the affected leg (Fig 2 after 5-year follow-up).

For the reasons cited above and based on my own experience, I consider combinations of KTS with spinal AVM to be possible, as described by Young et al (Table). ${ }^{3}$

\section{References}

1. Alomari AI, Orbach DB, Mulliken JB, et al. Klippel-Trenaunay syndrome and spinal arteriovenous malformations: an erroneous association. AJNR Am J Neuroradiol 2010;31:1608-12

2. Orszagh M, Schulte DM, Korinthenberg R, et al. Analysis of hemodynamics by MR-angio and embolization of Klippel-Trenaunay-Weber syndrome: five year follow-up. Revista di Neuroradiologia 1999;12 (suppl 2):127-31

3. Young AE, Ackroyd J, Baskerville P. Combined vascular malformations. In: Mulliken JB, Young AE, eds. Hemangiomas and Malformations. Philadelphia: Saunders; 1988:246-74

M. Schumacher University of Freiburg Department of Neuroradiology Freiburg, Germany

DOI 10.3174/ajnr.A2491

Comparison between KTS and Parkes-Weber Syndrome ${ }^{3}$

\begin{tabular}{|c|c|c|}
\hline & KTS & Parkes-Weber Syndrome \\
\hline Cutaneous vascular malformation & $\begin{array}{l}\text { Almost invariably tends to be dark; may be } \\
\text { verrucous }\end{array}$ & Frequent; usually a pink capillary malformation \\
\hline Arteriovenous fistulas & Not significant & Invariable ${ }^{a}$ \\
\hline Deep vein & Common ${ }^{\mathrm{a}}$ & Absent \\
\hline Lateral venous anomaly & Common $^{\mathrm{a}}$ & Absent \\
\hline Gigantism & $\begin{array}{l}\text { Usually disproportionate with soft-tissue thickening } \\
\text { predominating; often giant toes present }\end{array}$ & Usually proportionate \\
\hline Lengthening of limb & Usually minor & Often minor \\
\hline Associated lesions & Common & Rare \\
\hline Lymphatics & Often hypoplastic & Usually hyperplastic \\
\hline Prognosis & Good; stable after childhood & May be progressive deterioration \\
\hline
\end{tabular}

andicates signs present in our case. 

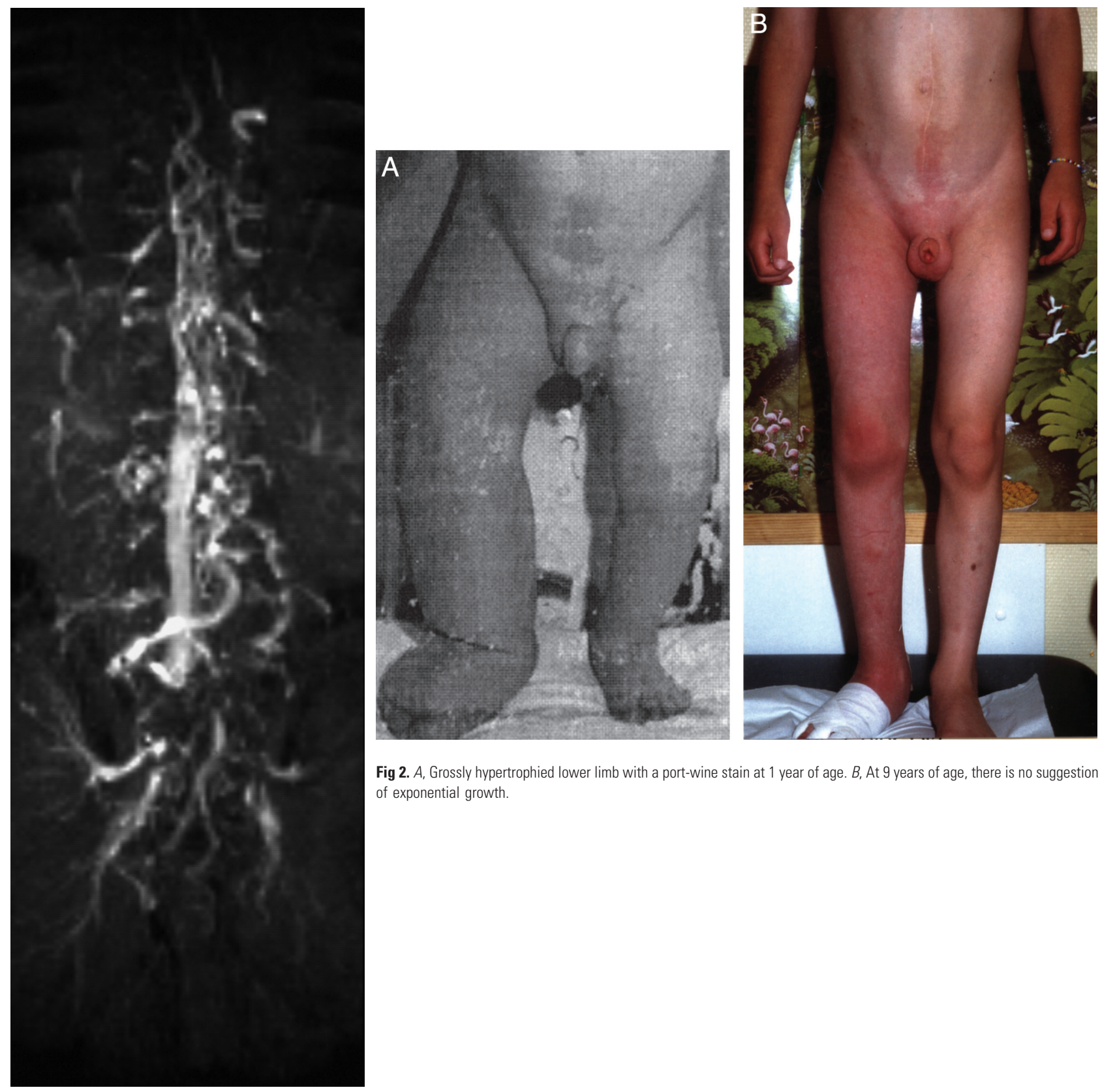

Fig 2. $A$, Grossly hypertrophied lower limb with a port-wine stain at 1 year of age. $B$, At 9 years of age, there is no suggestion of exponential growth.

Fig 1. 2D fast low-angle shot, before the first embolization at the age of 5 months, showing extremely voluminous segmental arteries and extensive intraspinal and paraspinal veins. 